Geopolítica(s) Revista de estudios sobre espacio y poder ISSN: 2172-3958

\title{
Entre pasado y futuro: la geopolítica crítica al cruce
}

Klaus Dodds, Merje Kuus y Joanne Sharp (eds.) (2013) The Ashgate Research Companion to Critical Geopolitics. Farnham: Ashgate. 570 pp. ISBN 978-14094-2380-5.

Por sus orígenes intelectuales y su evolución posterior, la geopolítica crítica es una disciplina intrínsecamente multifacética, que no se apoya en un único planteamiento teórico ni en una metodología universalmente compartida. Esta pluralidad de enfoques se refleja en The Ashgate Research Companion to Critical Geopolitics, que se propone ofrecer una perspectiva clara sobre el estado de la cuestión en esta materia. Para ello los editores han reunido algunos de los más reputados investigadores en el campo de la geopolítica crítica. En los veintiocho capítulos que componen el volumen, organizados alrededor de tres ejes principales, el Companion ofrece una perspectiva clara de lo que es - y de lo que ha sido - la geopolítica crítica, intentando al mismo tiempo avanzar propuestas para su agenda de investigación futura.

La primera parte del Companion —enfáticamente intitulada "Foundations" - se presenta como una introducción eficaz a los elementos clave de la geopolítica crítica. En los dos primeros capítulos, John Agnew y Simon Dalby delinean los orígenes históricos y conceptuales de esta disciplina, surgida al final de la Guerra Fría de la interacción entre geografía política y Relaciones Internacionales (RI) y del posestructuralismo. La denominación "geopolítica critica" supone, como observa Agnew (p. 27), una ruptura con el sentido tradicional del término "geopolítica". En efecto, si el saber geopolítico clásico defiende la idea de una relación de causa y efecto entre geografía y política, entre espacio y formas de organización de las comunidades humanas, la geopolítica crítica nace precisamente como un desafío a esta manera marcadamente determinista de concebir la relación entre espacio y poder. La geopolítica crítica lucha contra la fascinación que produce la posibilidad de poder alcanzar un saber objetivo de la realidad y del mundo. Más concretamente, como afirma Ó Tuathail ${ }^{1}$, la perspectiva crítica ve la geopolítica clásica como una serie de textos y discursos, elaborados por los "intelectuales de gobierno" (intellectuals of statecraft) y reproducidos a distintos niveles (geopolítica práctica y popular), que intentan establecer y aseverar sus propias verdades. La geopolítica

Gearóid Ó Tuathail: “Understanding Critical Geopolitics: Geopolitics and Risk Society”, Journal of Strategic Studies, 1999, vol. 22, núm. 2/3, p. 107. 
crítica, al contrario, apuesta por el cuestionamiento y por la deconstrucción de estos discursos. Y precisamente la fuerte centralidad del elemento discursivo y textual en el planteamiento crítico ha llevado algunos autores a hacer coincidir la geopolítica crítica con un análisis fundado (casi) exclusivamente en el estudio de textos y discursos $^{2}$. En palabras de Kelly:

Linking an understanding of foreign policy to elite scripts and discourse ignores the complexity of decision making, because to me a vast assortment of types and levels of groups and inputs contribute to state actions and goals that are not contained in the words of leaders. Organisational dynamics should fit into the calculus; likewise for domestic and international economic and political factors, personality idiosyncrasies, small-group machinations, international and regional structures, historic and cultural happenings, even luck and chance, and so on, the list being longer ${ }^{3}$.

Dicho de otro modo, tal y como lo explica Julien Mercille en su capítulo sobre geopolítica radical (p. 133), la geopolítica crítica no habría conseguido identificar las razones subrepticias de las políticas de los gobiernos y de los conflictos, quedándose a menudo en la simple descripción de cómo estos se despliegan y de la manera de representarlos. En este sentido, el capítulo de Martin Müller - intitulado "Text, Discourse, Affect and Things" (pp. 49-68)— podría parecer una respuesta adecuada a estas cuestiones, ya que en ello el autor aboga por una mejor sistematización del análisis discursivo en la geopolítica crítica. Más concretamente, Müller insiste en la necesidad - "mantener el vigor de la geopolítica crítica durante los siguientes 20 años"- de integrar el análisis discursivo con otros elementos, como las prácticas sociales (o sea, las formas que la geopolítica asume en la vida diaria), el papel del afecto en las representaciones geopolíticas, y la relación entre texto y materia. Con respecto a este último elemento, según lo explica Müller, hay que tener en consideración que el poder de las representaciones geopolíticas no descansa únicamente en los textos, sino en la compleja interacción de una "red sociomaterial de textos, personas y objetos" (p. 62). Y, según Müller, es en esta red donde la geopolítica crítica tendrá que moverse para cumplir con su agenda de emancipación.

Esta observación resulta particularmente pertinente, ya que otros autores han puesto en evidencia que la geopolítica crítica, a pesar de haberse convertido en la escuela geopolítica dominante en la geografía contemporánea, no ha conseguido "salir" del ámbito académico. Y es que, según ellos, la geopolítica crítica adolecería de ser "anti": "anti-geopolítica", "anti-cartográfica", hasta "antimedioambiental"4. Concentrémonos brevemente en la primera de estas tres etiquetas: ¿podemos efectivamente considerar la geopolítica crítica una "antigeopolítica"?

2 Véase Phil Kelly: “A Critique of Critical Geopolitics”, Geopolitics, 2006, vol. 11, núm. 1, pp. 24-53. También Neil Smith: "Is a critical geopolitics possible? Foucault, class and the vision thing", Political Geography, 2000, vol. 19, núm. 3, pp. 365-371.

3 Kelly: op. cit., p. 48.

4 Terrence W. Haverluk, Kevin M. Beauchemin y Brandon A. Mueller: "The Three Critical Flaws of Critical Geopolitics: Towards a Neo-Classical Geopolitics", Geopolitics, vol. 19, núm. 1, pp. 19-39. 
El argumento podría resumirse de la siguiente forma: al colocarse en oposición a los "intelectuales de gobierno", la geopolítica crítica se queda fuera de los círculos de poder. O, dicho de otro modo, la geopolítica crítica no puede influir en el proceso de toma de decisiones del gobierno y del aparato industrial-militar o, al menos, no directamente. Para sustentar sus tesis, los autores toman como ejemplo la ausencia de geógrafos en el equipo de expertos consejeros en política exterior del gobierno de Barack Obama y de sus predecesores. Hay aquí una crítica bastante singular. En primer lugar, porque los autores reconducen la geopolítica crítica a la sola anti-geopolítica, en su definición formulada por Routledge ${ }^{5}$. Y en segundo lugar porque la geopolítica crítica nace, como hemos dicho más arriba, precisamente como reacción al saber geopolítico producido por (y para) los gobiernos. Y si, por un lado, un mayor esfuerzo hacia la búsqueda de "canales de difusión" podría ser algo deseable, por otro lado, su distancia con respecto a los lugares de poder no es suficiente para invalidar su influencia, concreta o potencial. Más que sólo "antigeopolítica", la geopolítica crítica es un conjunto de maneras alternativas de pensar la relación entre espacio y poder.

El empleo del plural al hablar de geopolítica crítica es casi obligatorio, ya que, a partir de su "rechazo" del planteamiento clásico, ésta se ha efectivamente articulado en una multiplicidad de enfoques. Como observa Ó Tuáthail en su introducción al Companion, en efecto, "no hay una sola fórmula para hacer geopolítica crítica" (p. xxi), y esta pluralidad se pone de manifiesto en la variedad de las contribuciones presentadas en la obra: en particular, la segunda y tercera parte - respectivamente intituladas "Sites" y "Agents" - abordan un amplio abanico de temas. La segunda parte, como el título deja intuir, trata principalmente de lugares. El capítulo de Anssi Paasi sobre el estudio de fronteras (pp. 213-229) es un buen ejemplo de la capacidad del Companion de unir una visión de conjunto de las cuestiones abordadas con una perspectiva de su futuro desarrollo. Ahora bien, las partes más interesantes resultan ser quizás las "menos convencionales", como por ejemplo el excelente análisis del Sur Global de Chich Yuan Woon (pp. 323-340) y el capítulo sobre los espacios de terror de Ulrich Oslender (pp. 359-382): en el primero, el autor analiza la evolución del significado de Sur Global y cómo esta idea ha sido empleada en apoyo de los intereses socioeconómicos del Norte; en el segundo, Oslender discute de cómo se ha conseguido una territorialización del terror, es decir, la manera en que ciertos lugares del mundo hayan sido construidos como potencialmente o inherentemente peligrosos (p. 360). "Agents", la tercera y última parte de la obra, marca el compromiso de la geopolítica crítica con la exigencia de ir más allá del papel de los estadistas y de los oficiales de gobierno, para incluir en sus análisis una serie de actores (entre otros: periodistas, indígenas, mujeres, ONG) cruciales en la producción y reproducción de prácticas geopolíticas.

Quizás el escaso empleo del recurso cartográfico podría constituir un "punto débil" de la obra. Si nos fijamos en el Companion, en efecto, encontraremos apenas cuatro mapas en las casi seiscientas páginas que lo componen, y tres de ellos en el capítulo nueve, consagrado a la revaluación de las tradiciones geopolíticas ("Reappraising Geopolitical Traditions", pp. 165-187). Y es que estos mapas -el pivote geográfico de la historia de $\mathrm{H}$. J. Mackinder y otros dos mapas propagandísticos de

Véase el capítulo "Violence and Peace" del Companion, pp. 197-198. 
Alemania y Portugal en los años treinta - se emplean únicamente como blanco de las críticas. No hay, en este sentido, algún esfuerzo en proponer formas alternativas de representar gráficamente el espacio, aunque el argumento sea brevemente tratado en otros capítulos ${ }^{6}$. Aun así, habría que señalar que el tema de una cartografía crítica - aunque bastante marginal en el Companion - ha sido, y sigue siendo, objeto de interés en la disciplina ${ }^{7}$.

En definitiva, en lugar de una simple recopilación de la producción académica de los principales investigadores que se adscriben al enfoque crítico, el Companion pone de manifiesto la vivacidad intelectual de la geopolítica crítica a más de veinte años de su concepción. Se trata de una obra completa y sólida, cuyo mérito principal es contribuir a alimentar el debate acerca de lo que es y de lo que ha sido esta disciplina y, al mismo tiempo, avanzar propuestas concretas para su futuro desarrollo. La primera parte resultará particularmente útil para los que se acercan a la geopolítica crítica por primera vez. Y sin embargo, como se ha señalado anteriormente, esta obra muestra su verdadera fuerza una vez pasados los primeros capítulos, es decir, cuando aborda de manera más sistemática la compleja relación entre discursos geopolíticos y realdad material. Habrá que concordar con John Agnew cuando afirma: "No creo que los practicantes de la geopolítica crítica padezcan desempleo intelectual en los próximos años" (p. 30).

Emmanuele Quarta

Universidad Complutense de Madrid Email: emmanuele.quarta@gmail.com

6 Entre otros, el capítulo de Anssi Paasi ("Borders") y el de Alan Ingram ("Artists") tratan, aunque de forma breve, de la relación entre cartografía y geopolítica crítica.

7 Véase, por ejemplo, Anna W. Moore y Nicholas A. Perdue: "Imagining a Critical Geopolitical Cartography", Geography Compass, 2014, vol. 8, núm. 12, pp. 892-901. 